\title{
Mechanical Properties and Applications of Recycled Polycarbonate Particle Material Extrusion-Based Additive Manufacturing
}

\author{
Matthew J. Reich ${ }^{1}$, Aubrey L. Woern ${ }^{2}$, Nagendra G. Tanikella ${ }^{1}$ and Joshua M. Pearce ${ }^{1,3,4, *(1)}$ \\ 1 Department of Material Science and Engineering, Michigan Technological University, Houghton, MI 49931, \\ USA; mjreich@mtu.edu (M.J.R.); ngtanike@mtu.edu (N.G.T.) \\ 2 Department of Mechanical Engineering-Engineering Mechanics, Michigan Technological University, \\ Houghton, MI 49931, USA; alwoern@mtu.edu \\ 3 Department of Electrical and Computer Engineering, Michigan Technological University, Houghton, \\ MI 49931, USA \\ 4 Department of Electronics and Nanoengineering, School of Electrical Engineering, Aalto University, \\ 00076 Espoo, Finland \\ * Correspondence: pearce@mtu.edu; Tel.: +1-906-487-1466
}

Received: 23 April 2019; Accepted: 15 May 2019; Published: 20 May 2019

\begin{abstract}
Past work has shown that particle material extrusion (fused particle fabrication (FPF)/fused granular fabrication (FGF)) has the potential for increasing the use of recycled polymers in 3D printing. This study extends this potential to high-performance (high-mechanical-strength and heat-resistant) polymers using polycarbonate (PC). Recycled PC regrind of approximately $25 \mathrm{~mm}^{2}$ was 3D printed with an open-source Gigabot $X$ and analyzed. A temperature and nozzle velocity matrix was used to find useful printing parameters, and a print test was used to maximize the output for a two-temperature stage extruder for PC. ASTM type 4 tensile test geometries as well as ASTM-approved compression tests were used to determine the mechanical properties of PC and were compared with filament printing and the bulk virgin material. The results showed the tensile strength of parts manufactured from the recycled PC particles (64.9 MPa) were comparable to that of the commercial filament printed on desktop (62.2 MPa) and large-format (66.3 MPa) 3D printers. Three case study applications were investigated: (i) using PC as a rapid molding technology for lower melting point thermoplastics, (ii) printed parts for high temperature applications, and (iii) printed parts for high-strength applications. The results show that recycled PC particle-based 3D printing can produce high-strength and heat-resistant products at low costs.
\end{abstract}

Keywords: 3D printing; additive manufacturing; distributed manufacturing; polymers; polycarbonate; recycling; waste plastic; extruder; upcycle; circular economy

\section{Introduction}

The costs of additive manufacturing (AM) (notably material extrusion 3D printing) have dropped by several orders of magnitude with the open-source development of the self-replicating rapid prototyper (RepRap), which replaced proprietary fused deposition modeling (FDM) with the generic fused filament fabrication (FFF) [1-3]. With these cost declines came the real potential for a distributed manufacturing paradigm [4-6]: direct production by prosumers for significant cost savings compared to purchasing mass-manufactured products [7-13]. Economic analysis and the business literature support the growth of distributed manufacturing [14-20] because of the exponential rise of free 3D printable digital designs [12], which range from expensive scientific instrumentation [20-27] to everyday consumer items [10-13]. High return on investments (ROIs) are evident from the download 
substitution values using commercial 3D printing polymer filament $[28,29]$. Commercial filament, however, is generally marked up by more than five times to ten times the cost of raw plastic, which limits the cost savings and the concomitant deployment velocity of distributed additive manufacturing [30].

One method of overcoming the artificial cost barrier to distributed AM using material extrusion created by filament markups is to upcycle plastic waste into 3D printing filament with an open-source waste plastic extruder (recyclebot) [31]). The recyclebot process decreases the embodied energy of filament by $90 \%$ compared to traditional filament manufacturing [32-35]. This distributed recycling is a good example of an efficient circular economy [35], as it eliminates nearly all transportation embodied energy and pollution. Many recyclebot versions have been developed [36], including one that is primarily 3D printable and open-source [37]. Many types of waste polymers have been recycled into 3D printing filaments, including the most popular AM materials polylactic acid (PLA) [37-41] and acrylonitrile butadiene styrene (ABS) [35,42,43], as well as high-density polyethylene (HDPE) [31,43-45], polypropylene (PP) [45], polystyrene (PS) [45], polyethylene terephthalate (PET) [46], linear low-density polyethylene (LLDPE) and low-density polyethylene (LDPE) [47], elastomers [9], as well as composites using carbon reinforced plastic [48] and waste wood [49]-impregnated plastic. As the use of a recyclebot system introduces a melt extrude cycle that degrades the mechanical properties [50,51], recycling is limited to about five cycles [38,39] without blending with virgin materials. It is possible, however, to eliminate the need for filament entirely and print directly from particles, pellets, flakes, regrind, or shreds of recycled plastic. Such particle material extrusion (PME) 3D printers are also referred to as fused particle fabrication (FPF) or fused granular fabrication (FGF), and are becoming established in the academic [52-54], hobbyist [55,56], and commercial [57-61] arenas. Most systems were tested only with virgin pellets; however, two recent studies have shown enormous promise for PME printing of recycled materials in terms of both mechanical properties [62] and distributed manufacturing economics [63].

This study extends this potential to high-performance (high-mechanical-strength and heat-resistant) polymers using polycarbonate (PC) plastic. Recycled PC regrind was 3D printed with an open-source Gigabot X, and the material properties of the 3D-printed products were analyzed. A power and nozzle velocity matrix was used to optimize the print speed, and a print test was used to maximize the output for a two-temperature stage extruder for PC. ASTM type 4 tensile tests as well as ASTM compliant compression tests were used to determine the mechanical properties of PC and were compared with filament printing and the bulk virgin material. Three case study applications were investigated: (i) using PC as a rapid molding technology for lower melting point thermoplastics, (ii) printed parts for high-temperature applications, and (iii) printed parts for high-strength applications. The results are presented and discussed in the context of using waste PC directly for distributed manufacturing.

\section{Materials and Methods}

\subsection{Materials}

Clear PC regrind was provided by McDonnough Plastics, Fenton, MI, for $\$ 1 / \mathrm{lb}(\$ 2.20 / \mathrm{kg})$, to be used in the Gigabot X. The particle size characteristics of the starting material were quantified using digital imaging and the open-source Fiji/ImageJ [64] following a standard methodology [65] to determine the size distributions of the particles. Commercial PC filament with a consistent $2.85 \mathrm{~mm}$ diameter used for comparison printed on FFF was provided by Gizmodorks, Temple City, CA, USA [66].

\subsection{PME 3D Printer and FFF $3 D$ Printers}

A prototype Gigabot X (re:3D, Austin, TX, USA) $[67,68]$ was used to print the recycled PC particles. 3D models were sliced with Slic3r [69], and the printer was controlled with Marlin Firmware [70]. Due to the high temperatures needed to print $\mathrm{PC}$, and the lack of a print cooling system on the prototype Gigabot $X$, smaller prints (e.g., dimensions of only a few $\mathrm{cm}$ ) were malformed. Unlike conventional FFF 3D printers, the extruder head on the Gigabot $X$ is too large ( $250 \mathrm{~mm}$ long) to accommodate the 
two separate heating zones. The heating zones themselves are exposed and would melt any cooling fans attached near the extruder head. To overcome these challenges, $25 \mathrm{~mm}$ of fiber glass insulation was wrapped around the entire extruder system to contain the heat and allow for a cooling system to be attached. The cooling system itself was designed and released under an open-source license [71] and 3D printed out of PLA, which allowed two cooling fans to be attached (see Figure 1). The end of the extruder remained uninsulated and therefore still very warm, so the fans were designed to attach further up the extruder and two tunnels directed the air onto the printing surface. Comparisons between samples printed with and without the cooling system showed that perimeter walls were straighter and more uniform, and the cooling system was therefore used for the larger prints (tensile tests and applications).
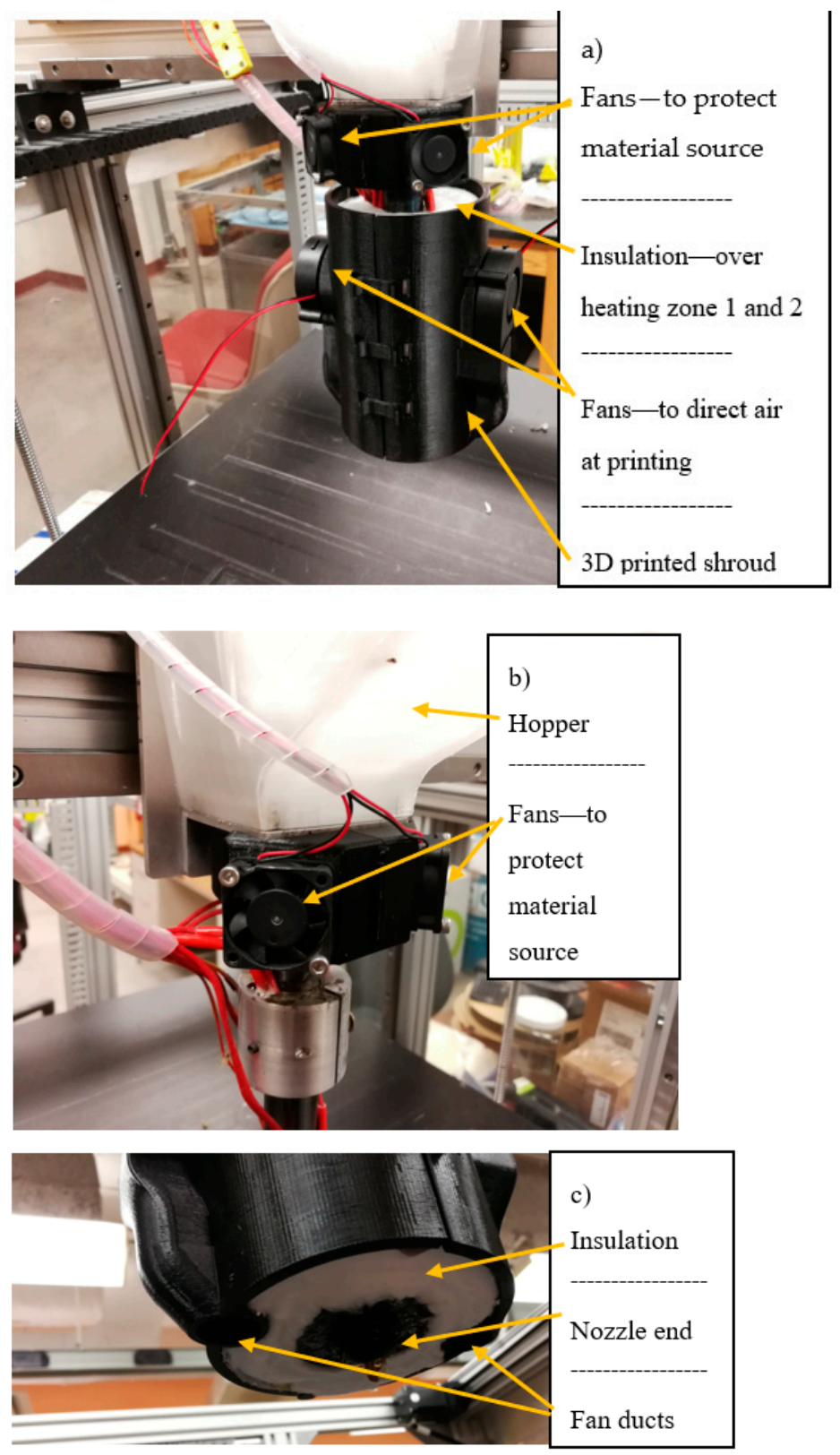

Figure 1. Gigabot $X$ prototype additional cooling system showing (a) installation, (b) fan attachment at hopper, and (c) nozzle end. 
To compare to conventional FFF, this study used both a desktop open-source Lulzbot TAZ 6 (Aleph Objects, Loveland, CO, USA) [72] as well as a conventional FFF-based Gigabot. Both printers were used to print PC filament with Lulzbot Cura 21.03 [73] slicer and Marlin firmware [69]. The TAZ 6 used a plexiglass enclosure to keep cool air drafts off the printer and keep some heat in.

The printing parameters for all three printers are summarized in Table 1. Please note that the tensile bars were printed flat on the bed with the $\mathrm{z}$ axis oriented perpendicular to the print bed. The orientation of the $100 \%$ infill was set at 45 degrees, creating an $x$ pattern down the length of the bars.

Table 1. 3D printer settings for all additive manufacturing (AM) systems tested.

\begin{tabular}{|c|c|c|c|}
\hline 3D Printer & FFF TAZ & FFF Gigabot & $\begin{array}{l}\text { PME/FPF } \\
\text { Gigabot X }\end{array}$ \\
\hline Layer height & $0.3 \mathrm{~mm}$ & $0.4 \mathrm{~mm}$ & $0.5 \mathrm{~mm}$ \\
\hline Nozzle diameter & $0.5 \mathrm{~mm}$ & $1.2 \mathrm{~mm}$ & $1.75 \mathrm{~mm}$ \\
\hline $\begin{array}{c}\text { Number of outer shells } \\
\text { on all surfaces }\end{array}$ & \multicolumn{3}{|c|}{$2 *$} \\
\hline Orientation of Infill & \multicolumn{3}{|c|}{ Rectilinear at 45 degrees with respect to long axis of tensile bars } \\
\hline Infill & \multicolumn{3}{|c|}{$100 \%$} \\
\hline Speed & $30 \mathrm{~mm} / \mathrm{s}$ & $20 \mathrm{~mm} / \mathrm{s}$ & Variable, $10 \mathrm{~mm} / \mathrm{s}$ \\
\hline Temperature & $270{ }^{\circ} \mathrm{C}$ & $250^{\circ} \mathrm{C}$ & $\begin{array}{l}250-260, \text { zone } 1 \text { and } 2 \text { (after } \\
\text { velocity temperature test) }\end{array}$ \\
\hline Bed temperature & \multicolumn{3}{|c|}{$110^{\circ} \mathrm{C}$} \\
\hline
\end{tabular}

\subsection{Temperature and Velocity Test}

Testing procedures previously described for the PME platform [62] were used. The temperature vs. velocity matrix test for PC was accomplished by first identifying the upper and lower bounds of the printable temperature range. Typical desktop FFF-based PC printers print at around 250 to $310^{\circ} \mathrm{C}$, but to test a wide range of temperatures, the Gigabot $\mathrm{X}$ was set to continually extrude material, while the temperature was manually raised and lowered to find the physical upper and lower limits. An initial value of $260^{\circ} \mathrm{C}$, the melting temperature of polycarbonate, was slowly lowered until the PC solidified enough where extrusion was no longer possible for the stepper motor powering the screw. At $230^{\circ} \mathrm{C}$, the motor started skipping, so a lower limit was of $240{ }^{\circ} \mathrm{C}$ was used. On the opposite side of the temperature range, the Gigabot $\mathrm{X}$ was set to $300^{\circ} \mathrm{C}$, but due to moderate heat loss around the extruder, heating zone 2 only reached $270{ }^{\circ} \mathrm{C}$ and heating zone 2 reached $290{ }^{\circ} \mathrm{C}$. These values were used as the upper limits. The tip of the nozzle (heating zone 1 ) and inside the barrel (heating zone 2 ) were set to every combination of temperatures in the printable temperature range at a resolution of $10{ }^{\circ} \mathrm{C}$. A series of double lines was then printed at each temperature combination at print speeds from 5 to $50 \mathrm{~mm} / \mathrm{s} \mathrm{in}$ $5 \mathrm{~mm} / \mathrm{s}$ increments. The printed lines were then massed on a digital scale $( \pm 0.01 \mathrm{~g})$, and the line masses were compared to the theoretical line mass. The objective of this test was to find both the optimum print speed and the temperature settings for the extruder (both heat zones). The optimization was determined for settings, with the lowest standard deviation in the line weight for a set of lines and the print speeds across all the temperature settings that resulted in the heaviest line masses.

Once the print temperatures that obtained a close-to-theoretical value were found for each zone, a single-walled cylinder, printed as a spiral vase, was used to determine the extrusion multiplier and actual extrusion width of the polycarbonate. The cylinder, measuring $5 \mathrm{~cm}$ high and $10 \mathrm{~cm}$ in diameter, was printed and massed. The measured mass was compared to the theoretical mass, which was calculated using the volume of the material that made up the cylinder walls (theoretical) and the specific density of PC (theoretical). Proportions between the measured and theoretical masses, 
and multiple cylinder trials, were used to find the appropriate slicer extrusion multiplier and therefore the ideal flow rate for the settings tested to use for PC. After this was accomplished and 3D printing was carried out with the correct flow rate, digital calipers $( \pm 0.005 \mathrm{~mm})$ were used to find the printed wall thickness. Input into the slicing software (Slic3r) [69], this value would ensure print quality for the remaining tests as the lines would be the correct width.

\subsection{Tensile Testing}

Tensile testing was completed for the recycled PC using ASTM D638 Type 4 standard tensile bar geometry, and this same geometry was used for the FFF processed PC as outlined in Table 1 [74]. For the recycled PC, the bars were printed at the print settings that provided a close match to the theoretical mass found in Section 2.3 with 100\% infill with an infill pattern of 45 degrees with respect to the long axis of the tensile bars. The specimens were then pulled until failure using a 10,000 lb. load cell (Model LCF455). The strain data was captured using the crosshead extension on the Universal Testing Machine.

\subsection{Compression Testing}

Compression testing was done using the same load cell (Model LCF455). Three different samples were chosen for compression: (1) cylinders with diameter $15 \mathrm{~mm}$ and length $30 \mathrm{~mm}$ (printed vertically), (2) rectangular prisms with length of $28 \mathrm{~mm}$ and thickness and width of $14 \mathrm{~mm}$ (printed vertically), and (3) rectangular prisms with length of $28 \mathrm{~mm}$ and thickness and width of $14 \mathrm{~mm}$ (printed horizontally), in accordance with the ASTM D695 standards. The specimens were printed with 100\% infill in a 45-degree pattern. The compression specimens did not break, and hence they were tested to an arbitrary level of deformation (10\%), in accordance with the ASTM standards.

\section{Results}

\subsection{Materials Size Distribution}

Previous work [62] concluded that pellets with areas smaller than $22 \mathrm{~mm}^{2}$ could feed into the auger of the Gigabot $X$ regardless of shape. A digital image of the input recycled $P C$ is shown in Figure 2, which displays the size distribution of unsifted and sifted particle sizes, respectively. Initially, printing with the regrind particles without sifting was problematic due to the substantial PC particles size distribution. Larger particles would log themselves between the auger and the side of the hopper, causing the extruder to stop and the stepper motor to skip until the printer was shut down. To solve this problem, a sifter with holes approximately $5.5 \mathrm{~mm}$ in diameter was used to sift out the larger particles. As seen in Figure 2, the sizes of the sifted particles are considerably smaller than that of the unsifted particles, and mostly fall under the $22 \mathrm{~mm}^{2}$ recommendation. Without the larger PC particles, the auger was able to extrude the material without clogging and therefore produced a much more reliable print system.
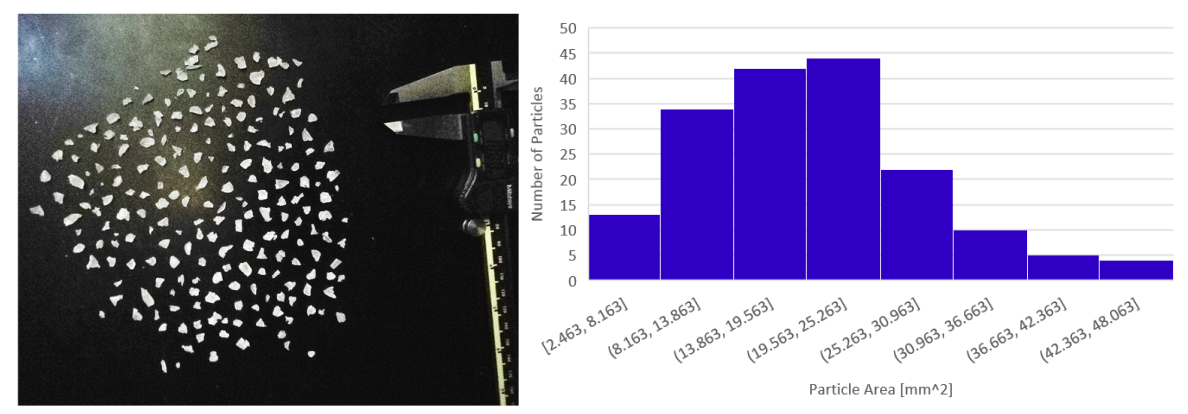

(a)

Figure 2. Cont. 

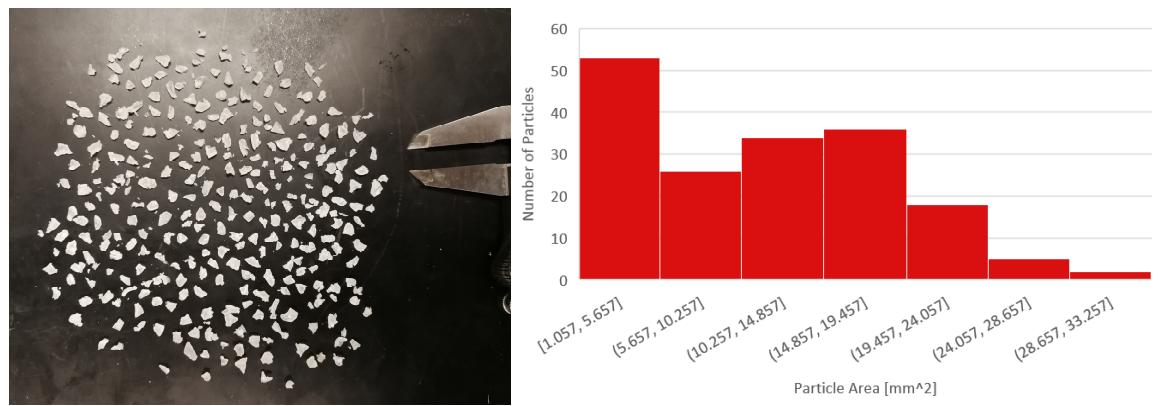

(b)

Figure 2. Recycled polycarbonate (PC) particles and size distribution, unsifted (a) and sifted (b).

\subsection{Printing Temperatures and Velocities}

The masses of the printed double lines were recorded in a matrix generated over the range of the operating temperatures for the two heating zones and the nozzle velocities from 5 to $50 \mathrm{~mm} / \mathrm{s}$. The difference between the theoretical and the actual mass of the line was recorded and is shown as a function of the nozzle speeds in Figure 3. The colors shown in Figure 3 are merely meant to act as eye guides and represent the relationship between the printed lines and theoretical mass; the darker green tone of the box around the number is, the closer to the theoretical value it is (the deeper red the further away). Figure 3 can be simply read by only looking at the numerical values. The ideal would be zero, i.e., the measured mass is equal to the theoretical. The average and standard deviation portion of the chart work similarly. The standard deviation measures how much each mass in a sample differs other masses in the same sample, and a lower standard deviation shows higher consistency in the print.

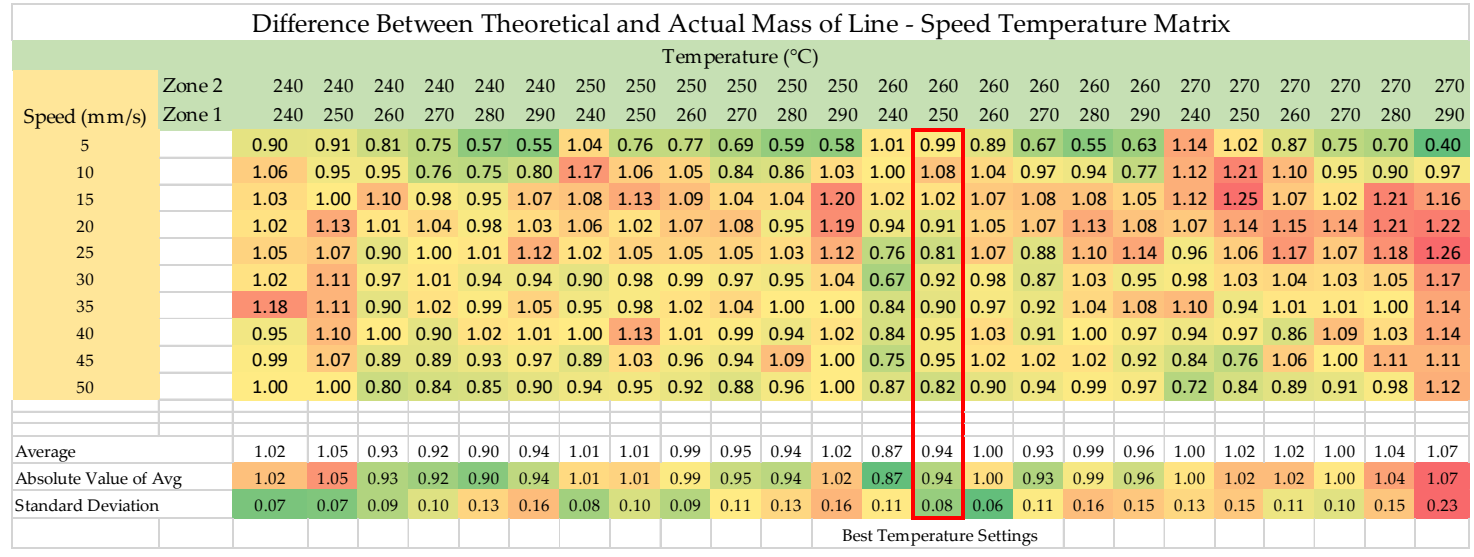

Figure 3. PC difference between the theoretical and actual mass of the line-speed temperature matrix.

Figure 3 shows the results for the recycled PC. The temperatures that provide values closest to the theoretical values were found to be $250{ }^{\circ} \mathrm{C}$ and $260{ }^{\circ} \mathrm{C}$ for heating zones one and two, respectively. As seen in Figure 3, none of the printed lines were very close to the theoretical mass. The best combination of temperatures was chosen based on its low standard deviation and respectably average value. Looking at data collected for $5 \mathrm{~mm} / \mathrm{s}$ only, there is a positive correlation between temperature and proximity to the theoretical value. The higher the combined temperature of the heating zones, the closer the mass of the lines was to the theoretical values. Had this trend continued throughout all printing speeds, the highest temperature settings would have produced the best print, but due to the inconsistencies between the lines printed at faster speeds, this conclusion could not be met.

Observing the trend in the average line weight speeds across the full temperature spectrum, line weight is maximized at print speeds of around $5 \mathrm{~mm} / \mathrm{s}$, as shown in Figure 4. At this print speed, the volumetric deposition rate is $5 \mathrm{~mm}^{3} / \mathrm{s}$. In comparison, a traditional FFF printer at this speed, with a 
layer height of $0.2 \mathrm{~mm}$ and a $0.4 \mathrm{~mm}$ nozzle, will average $0.4 \mathrm{~mm}^{3} / \mathrm{s}$. This translates to a 12.5 times increase in the 3D-printed part formation and therefore concludes that overall print time can be greatly reduced using the Gigabot $X$.

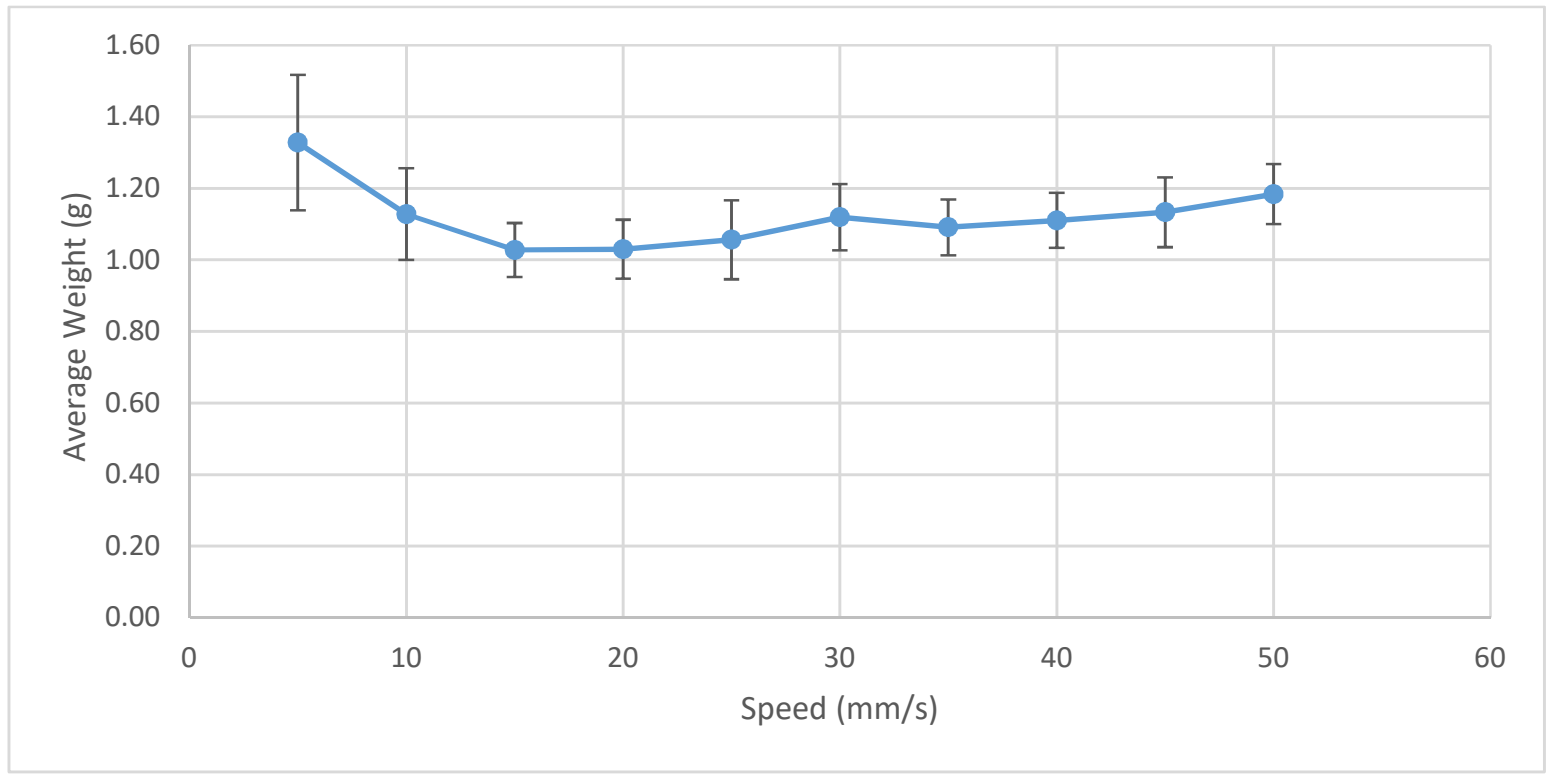

Figure 4. PC average mass as a function of the print speed.

\subsection{Mechanical Testing}

\subsubsection{Tensile Testing}

The peak stresses/ultimate tensile strengths (UTS) for the specimens printed on the Gigabot $X$ with PME/FGF ranged from 62.7 to $67.8 \mathrm{Mpa}$, with an average of $64.9 \mathrm{MPa}$ and a standard deviation of 2.1 MPa. The peak stresses for the specimens on the FFF-based Gigabot were $63.0 \mathrm{MPa}$ to $69.5 \mathrm{Mpa}$, with an average of $66.3 \mathrm{MPa}$ and a standard deviation of $2.9 \mathrm{MPa}$. The peak stresses for the samples 3D printed on the FFF-based TAZ ranged from 59.5 to $66.8 \mathrm{Mpa}$, with an average of $62.2 \mathrm{MPa}$ and a standard deviation of $2.8 \mathrm{MPa}$. The crosshead data shows a higher extension on the Gigabot $\mathrm{X}$ specimens (average $4.7 \mathrm{~mm}$ ) when compared with the TAZ specimens (average $4.2 \mathrm{~mm}$ ). The differences between the Gigabot X, FFF-based Gigabot, and the FFF-based TAZ samples could be due to several factors, including source of material, color of material, additives, layer height, temperature of extruder, speed of print, and size of nozzle. However, the samples are similar enough for the recycled material to be considered an alternative to the commercial filament on conventional FFF-based printers. However, it should be noted again that the Gigabot $X$ is not appropriate for printing small samples with high resolution due to the large nozzle diameter.

\subsubsection{Compression Testing}

The average compressive stresses at 10\% deformation for the three sample geometries printed on the Gigabot $X$ and the TAZ are shown in the Table 2. Compression tests show that components printed on the TAZ withstand higher stresses for the same deformation and have a lower standard deviation than the samples printed from recycled PC on the Gigabot X. 
Table 2. Compression tests.

\begin{tabular}{ccccc}
\hline \multicolumn{4}{c}{ Average Stress at 10\% Deformation (MPa) } \\
\hline $\begin{array}{c}\text { Open-Source 3D Printer } \rightarrow \\
\text { Sample Geometry } \downarrow\end{array}$ & Gigabot X & Std Deviation & TAZ FFF & Std Deviation \\
\hline Cylinder & 50.8 & 5.2 & 68.1 & 1.4 \\
\hline Prism (vertical) & 60.9 & 7.3 & 70.4 & 1.3 \\
\hline Prism (horizontal) & 43.3 & 17.6 & 77.3 & 1.8 \\
\hline
\end{tabular}

For the Gigabot $X$, the rectangular prism sample printed horizontally has the lowest average stress and the highest standard deviation because the test specimens all were wider and longer at the base and tapered along the height. Thus, they sheared and broke into layers instead of compressing. Specimens printed vertically also had inconsitencies, which allowed compression of the smaller regions. However, this effect did not effect the type of deformation. Thus, the compression sample printed vertically has a higher strength. Furthermore, the prism sample has a higher strength than the cylindrical sample.

For the TAZ, there was little difference between the strength of the cylindrical sample and the prism sample printed vertically due to better reproduction at small scales with the smaller print head. The prism sample printed horizontally had higher strength than the prism sample printed vertically. It can be concluded that for applications involving small-scale products under compression, recycled PC printed with a Gigabot X cannot be used as a drop in replacement for PC on a conventional FFF printer. However, these effects would be expected to become less pronounced the larger the object printed. Future work is needed to quantify the effect of less consistent printing over the compressive strength of larger objects.

\subsection{Case Studies}

To determine the economics of printing PC on the Gigabot X, material and electric costs were analyzed. The material costs as a function of time were found by printing multiple standard parts at optimum speed and flow rate. Print times for each part were recorded; each part was massed on a digital scale $( \pm 0.01 \mathrm{~g})$, and the average material flow for the was found to be $0.037 \mathrm{~kg} /$ hour. With a material cost of $\$ 2.20 / \mathrm{kg}$, the Gigabot $X$ would cost $\$ 0.074 /$ hour to run based purely on materials. While printing at the temperatures, $260^{\circ} \mathrm{C}$ for zone two, $250{ }^{\circ} \mathrm{C}$ for zone one, and $110^{\circ} \mathrm{C}$ for the bed, and while the added cooling system was running, electricity use was monitored with a multimeter. With an average electricity cost of $\$ 0.1029 / \mathrm{kWh}$ in the US over all sectors [75], the Gigabot X costs approximately $\$ 0.13 /$ hour in electricity to operate. Combined, the operational cost of the Gigabot $X$ to print recycled PC is $\$ 0.204 /$ hour.

Three case studies were used to test the recycled PC in PME/FGF applications. To take advantage of the high melting point of PC, low-cost molds were designed for use in a basic injection molding device. When many parts need to be made quickly, or when hard to print plastics are required, an injection molding machine and molds can be the best solution. This molding machine consists of a metal tube surrounded with heating elements and a plunger to push material through the hot zone into the mold. The tube is filled with plastic and the mold is then screwed onto the heated tube with a flange, and the plunger pushes the molten plastic into the mold cavity. Muhammad et al., using this method, 3D-printed molds from ABS after failed attempts at printing large water fixtures with recycled HDPE waste in the Solomon Islands [76,77]. Here, this method was improved by replacing ABS molds with molds from PC, which allowed for a larger quantity of parts to be made before the mold wore out as well as for higher temperature waste plastics to be used. An STL rendering of a mold made for compression specimens is shown in Figure 5. In addition, case studies of a consumer high-temperature application (steam cleaner) and high-strength application (ice scraper) were fabricated and tested. 


\subsubsection{Rapid Molding Technology for Lower Melting Point Thermoplastics}

Waste PC was successfully manufactured into a mold (design shown in Figure 5) that can be used for rapid molding of lower melting point thermoplastics.

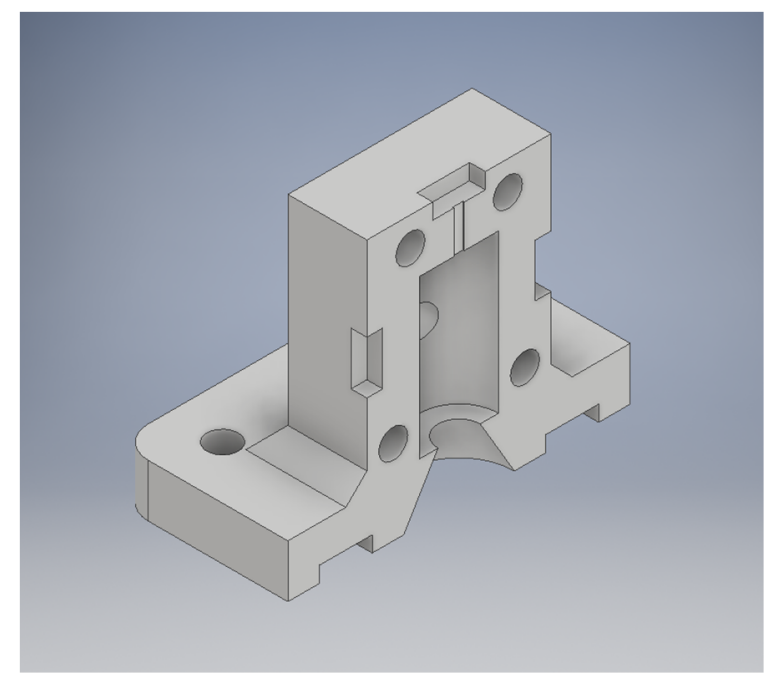

Figure 5. STL rendering of compression specimen mold.

This is demonstrated in Figure 6 for a TPU composite. Following [76,77], this technique can be used for distributed recycling of waste polymers in resource-constrained communities. It can also be used in any setting that needs multiple copies of a plastic product and is particularly effective for hard-to-print thermoplastics, as well as in abrasive composites that may damage a recyclebot or a tool like the Gigabot $X$.

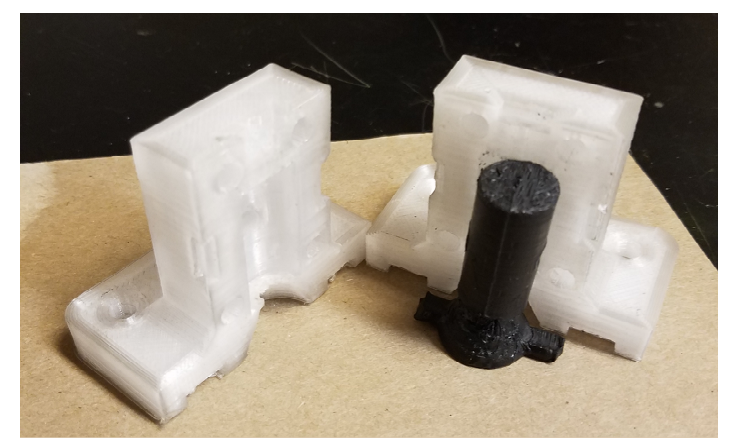

Figure 6. 3D-printed compression specimen mold with molded part.

\subsubsection{High-Temperature Applications}

It has long been the practice of some consumer product vendors to manufacture for obsolescence as well as use lower-cost non-optimal materials. An example of this is shown in Figure 7, a home floor steamer whose outer plastic has disintegrated under normal use. There is no replacement part available on the market, so a replacement was designed to be optimized for ease in 3D printing (as shown in Figure 8) and made available under an open-source license [71]. The design is made specifically to be $3 \mathrm{D}$ printed and uses no connecting hardware (as was done in the commercial design). The horizontal holes lock the three components together using the common filament rivet technique. Filament of PC can be produced from PC shards with the Gigabot X by simply extruding into air. The final assembly is completed using a soldering iron to melt the rivets into place. The only design feature used from the original design for the replacement was basic geometry to fit the existing cloth mop head, the sizing of 
the holes to fit onto the mop handle, and the hole for the steam tube. Thus, the new design is a true new design, not a reverse-engineered one or a copy.

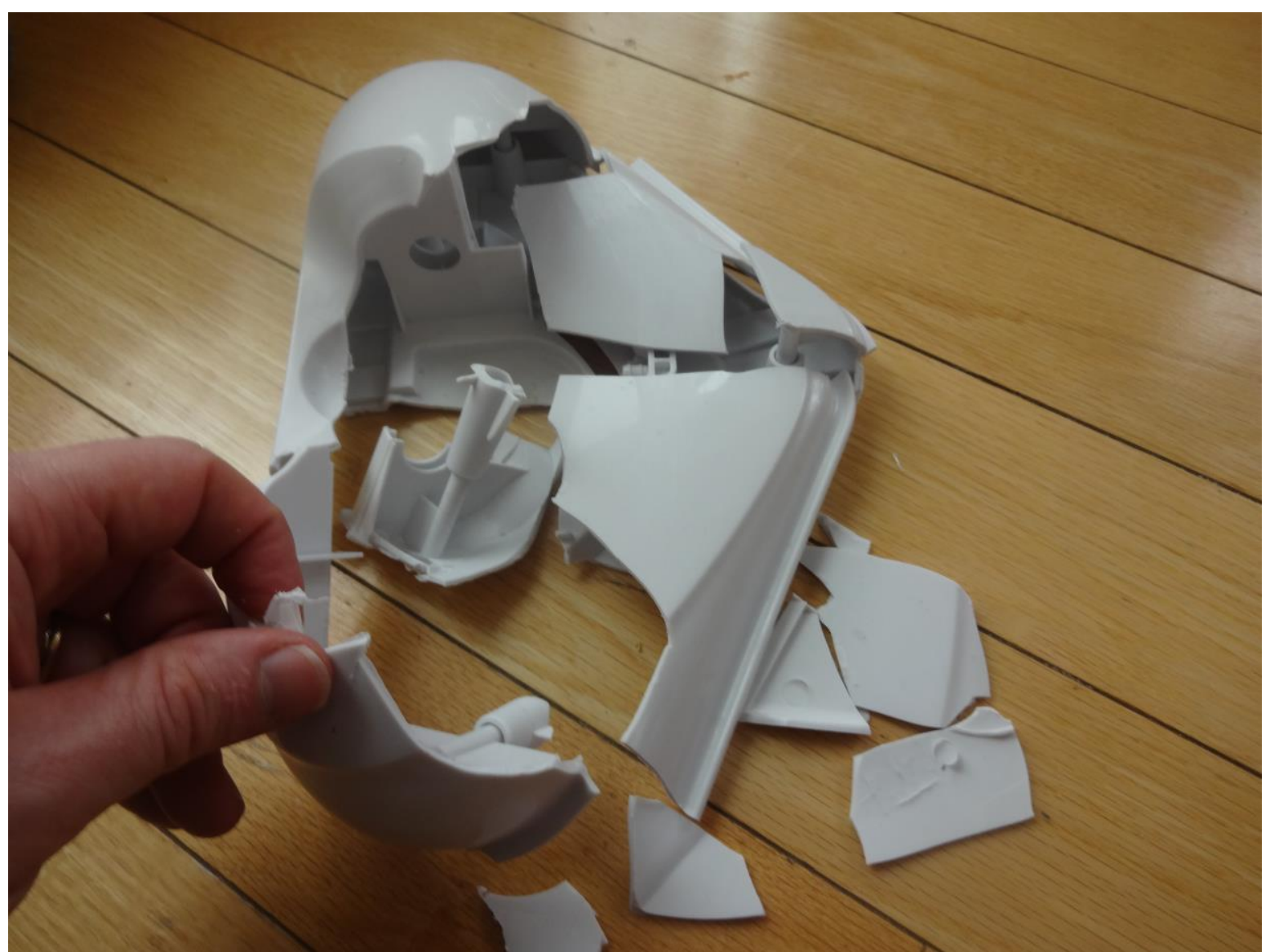

Figure 7. Broken commercial proprietary steamer head. The plastic became brittle and disintegrated under normal use.

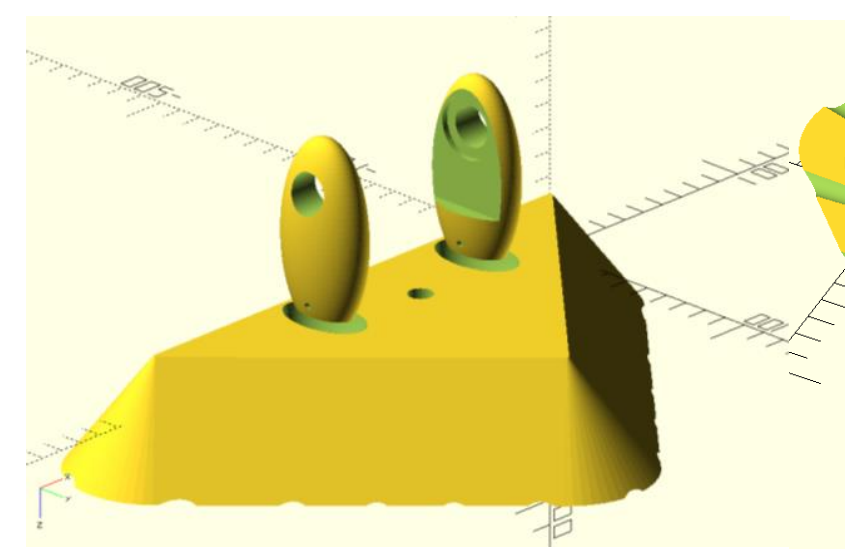

(a)

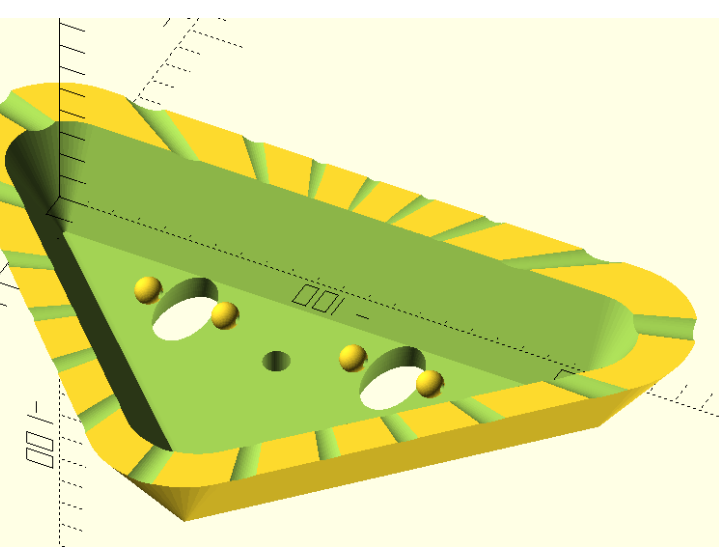

(b)

Figure 8. Rendering of OpenSCAD design of replacement steamer (a) top view and (b) bottom view.

The steamer head as shown in Figure 9 was 3D printed in PC waste and tested. It successfully performed the same function-essentially guiding the steam from a flexible nozzle to the floor where a cloth was used for wiping (note: cloth being held back in Figure 9 to see 3D-printed part). This 3D print, which used about $520 \mathrm{~g}$ of waste PC and cost about US $\$ 2.50$ to print successfully (including material and electricity costs), eliminated the need to buy an entirely new replacement steamer, which 
can be purchased from US\$59-US\$199 on Amazon [78]. Thus, printing replacement parts with recycled PC on the Gigabot X represents a $95 \%$ to $99 \%$ savings from purchasing new consumer goods made from materials with designed obsolescence.

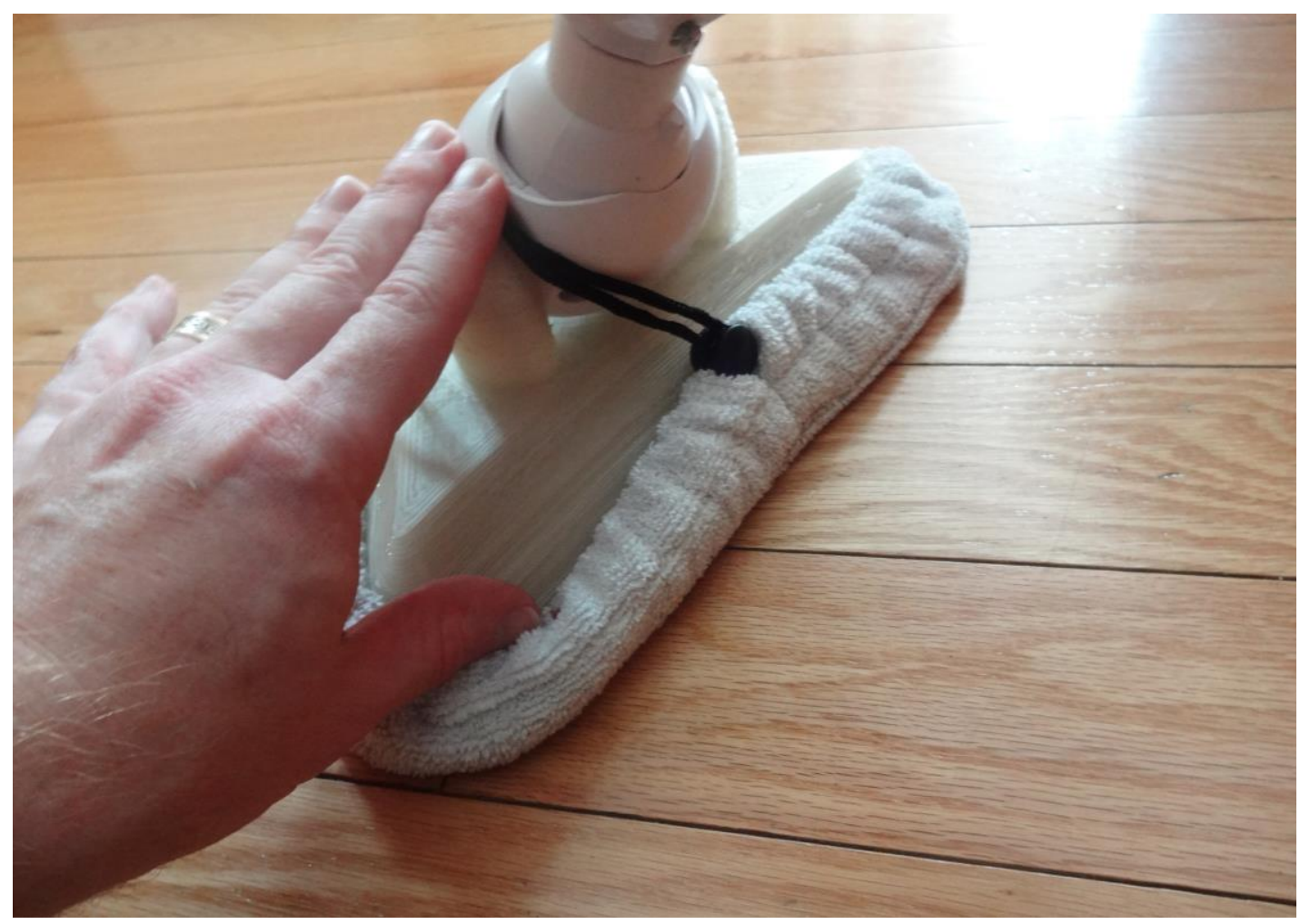

Figure 9. Waste PC 3D-printed steamer head shown assembled on steamer.

\subsubsection{Printed Parts for High-Strength Applications}

To exhibit the high-strength properties of the PC, an open-source (CC-BY licensed) car window ice scraper designed in Russia with interchangeable blades [79] (Figure 10) was printed and tested (Figure 11). The blade (Figure 10a) was printed in recycled PC. The handle was printed out of poly lactic acid (PLA) (Figure 10b) on a TAZ 6.

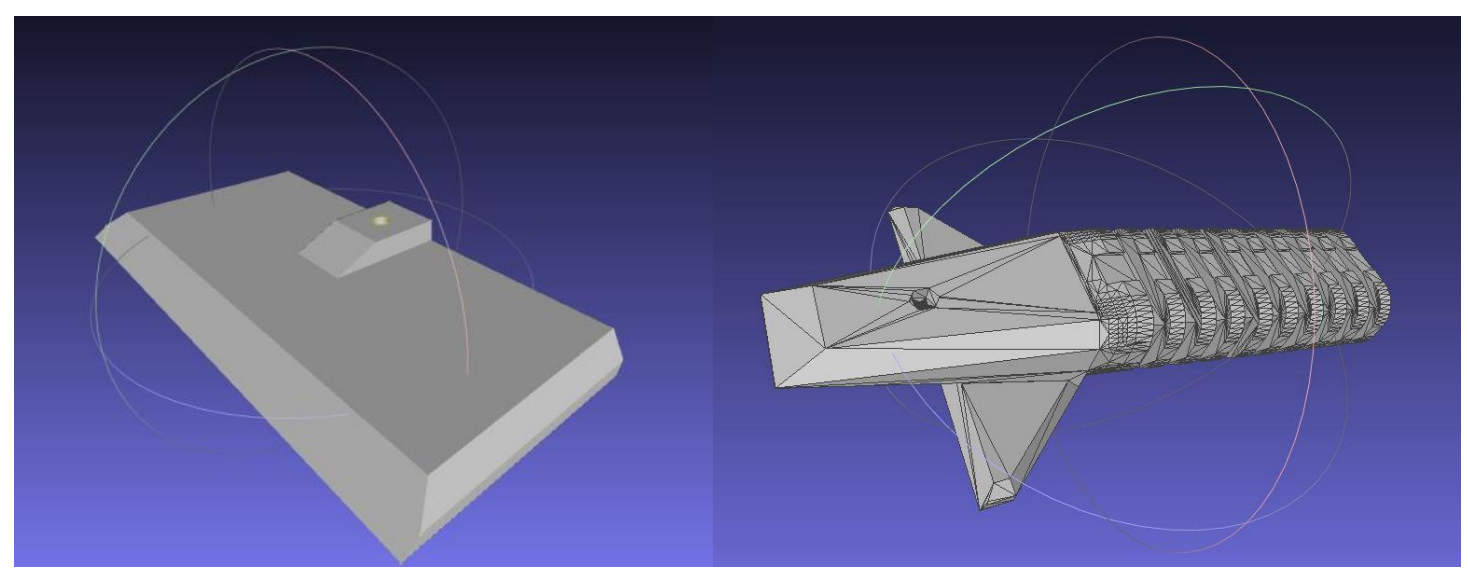

(a)

(b)

Figure 10. Meshlab rendering of STLs for (a) blade and (b) handle of snow scraper.

The strength of the PC gives the blade of the scraper the desired ability to scrape away ice and snow buildup on windshields without breaking or chipping. The recycled PC blade was tested over a 
winter of normal use in the upper peninsula of Houghton Michigan, which receives an average of $5.54 \mathrm{~m}$ of snowfall during the roughly 6-month winter. The blade remained strong and functional. In addition, being able to bend without breaking because of fabrication with PC enabled the blade to form to the windshield while in use.

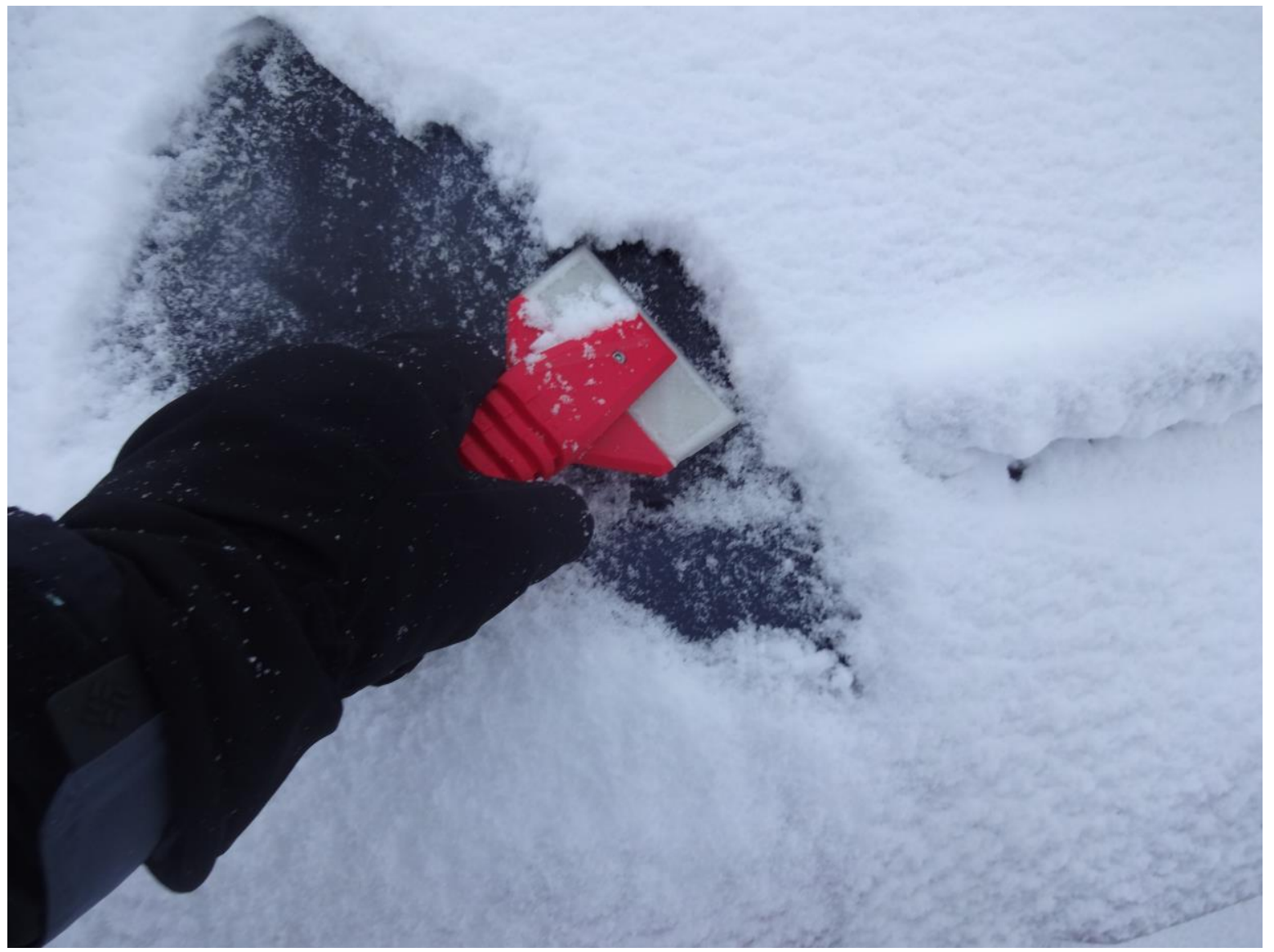

Figure 11. 3D-printed ice/snow scraper in use. The blade is recycled PC and the handle is polyactic acid (PLA).

\section{Discussion}

Previous research has shown that 3D printing recycled particles with a Gigabot X as opposed to commercially sold filament can substantially lower the costs of printing, decrease print time (because of the large nozzle), and increase ease of printing large objects $[62,63]$. This latter point is particularly important when printing objects that would use more than one spool of filament [80]. These conclusions were confirmed here with PC, as the costs for printing recycled PC material are roughly $2.5 \%$ of the costs of printing with commercial PC filament. The case studies showed that distributed manufacturing of recycled PC with an PME/FPF printer was useful over a wide range of applications that require both (e.g., molding) or either high temperature resistance (e.g., steamer head) or high strength (e.g., ice scraper). PME/FPF of recycled PC allows for a wider range of needs to be filled. The large nozzle size and increased volumetric deposition rate grants the Gigabot $X$ the ability to manufacture big components able to resist heat, and some high-strength properties. Applications include sporting equipment, personal protection, household appliance fixes, scientific instrumentation, and hand tool modifications. There remain some challenges in some areas of the world. For example, although China has a recycling symbol [81] for polycarbonate (58) in the U.S., it is grouped with dozens of other polymers in the other category (7) [82]. The open-source 3D printer community has already discussed the adoption of a voluntary recycling code based on the more comprehensive Chinese system [83]. This may be of modest help now as distributed manufacturing is still in its infancy; however, as the global 
value chains [16] shift because of the superior economics of distributed recycling and manufacturing, the prosumer community will benefit from regulations that stipulate that manufacturers identify the materials in their products [84]. This can go beyond primary polymers to list colorants, plasticizers, and other additives to better improve the ease of recycling.

This study also showed that the tensile strength of 3D-printed parts made from recycled PC was comparable to those made with conventional filament used in a conventional RepRap-class FFF 3D printer. Prior work on other materials $[85,86]$ has shown that RepRap-class FFF 3D-printed parts are often superior to the more constrained printing parameters used in proprietary fuse deposition modeling (FDM) machines. For small nozzle heads, using smaller type iv FFF tensile samples was shown to be adequate [87], and those results were also confirmed here with the larger nozzle size of the PME/FPF head used. However, the larger head was found to be a problem when attempting to obtain reliable small-scale compression samples. Further work is required for large-volume compression samples to determine large area compressive strength, as the results shown here can be considered a pessimistic under estimate of the recycled PC compressive strength. In addition, in the results shown by the double line tests, higher print temperatures increase the line mass, but only for $5 \mathrm{~mm} / \mathrm{s}$. Future work at higher temperatures for $5 \mathrm{~mm} / \mathrm{s}$ and other speeds may lead to ideal temperature combinations and improve the mechanical properties of the PC further. Printing at higher temperatures, which is possible because of the improved insulation around the extruder, might increase layer adhesion and improve print quality as well. Full optimization studies can also be run on layer height, print speeds, temperature, print orientations, etc. These optimization studies would ideally compare FFF with the same nozzle size to the PME/FPF for both recycled and virgin PC. In addition, past work on other materials that have gone through multiple 3D printing and recycling cycles have shown a degradation in the polymers and a reduction in mechanical strength [38,39]. Similar studies should be performed on multiple cycles of PC on both a PME/FPF printer and a conventional FFF printer to quantify the benefits of the reduced numbers of melts necessary in PME per cycle. Finally, the entire PME/FPF apparatus could be enclosed, which would again be likely to improve printed part quality and is left for future work.

Fortunately, there has been a noticeable increase in recent studies on 3D printers capable of using pellets as a feedstock, including those derived from metal injection molding [88,89], double stage screw extruders [90], RepRap technology [91], and industrial robots [92]. The study here provided further evidence that such machines could be used for recycled materials, as PC is a more challenging printing polymer because of its higher temperatures and higher strengths (e.g., if bed adhesion is sub-optimal and the print begins to deform, a PC print will often fail because of mechanical contact with the print head more often than weaker polymers like ABS). There is thus considerable future work to begin to apply PME/FPF printing to composites (ideally made from waste) such as for conductive materials [93] and flexible materials [94]. The results of both this study and previous studies on FGF and PME/FPF infer this type of 3D printing will play a larger role in the additive manufacturing industry in the future.

\section{Conclusions}

The results of this study found that sifted recycled PC shards could be effectively used as feedstock for PME/FPF additive manufacturing directly with a Gigabot X. Printing parameters that obtained close to theoretical values of mass were found to be 250 and $260{ }^{\circ} \mathrm{C}$ for printing zones 1 and 2, respectively, at $5 \mathrm{~mm} / \mathrm{s}$. The average peak stress for recycled PC on the Gigabot X prints was $64.9 \mathrm{MPa}$ and a standard deviation of $2.1 \mathrm{MPa}$, indicating that it can be used as a drop-in replacement for 3D-printed PC parts on a standard FFF printer using conventional filament. The compressive testing was less conclusive, although it is clear that inconsistent depositions on small scales create weaker compressive strength than the same material deposited with a smaller print head. Substantially faster printing speeds are possible (10X) because of a larger printing nozzle diameter without a substantial decrease in performance, although future work is needed to further optimize the system for recycled PC shards. Recycled PC particles has been proven to be an inexpensive and useful material to use for additive 
manufacturing on PME/FPF 3D printers. The viability of recycled PC particles offers a wide range of uses that can replace more expensive solutions for prosumers and industry alike.

Author Contributions: Conceptualization, J.M.P.; Data curation, M.J.R., A.L.W. and N.G.T.; Formal analysis, M.J.R., A.L.W., N.G.T. and J.M.P.; Funding acquisition, J.M.P.; Methodology, A.L.W., N.G.T. and J.M.P.; Validation, M.J.R.; Writing—original draft, M.J.R. and J.M.P.; Writing—review and editing, M.J.R., A.L.W., N.G.T. and J.M.P.

Funding: This research was supported by re:3D, Aleph Objects, NSF SBIR program, and the Richard Witte Endowment.

Acknowledgments: The authors would like to acknowledge helpful comments, suggestions, and technical support from Samantha Snabes and Matthew Fielder.

Conflicts of Interest: The authors have no conflict of interest. The funders played no part in the design of the study; in the collection, analyses, or interpretation of the data; in the writing of the manuscript; or in the decision to publish the results.

\section{References}

1. Sells, E.; Bailard, S.; Smith, Z.; Bowyer, A.; Olliver, V. RepRap: The Replicating Rapid Prototyper-Maximizing Customizability by Breeding the Means of Production. In Proceedings of the World Conference on Mass Customization and Personalization, Cambridge, MA, USA, 7-10 October 2007.

2. Jones, R.; Haufe, P.; Sells, E.; Iravani, P.; Olliver, V.; Palmer, C.; Bowyer, A. RepRap-the Replicating Rapid Prototyper. Robotica 2011, 29, 177-191. [CrossRef]

3. Bowyer, A. 3D Printing and Humanity's First Imperfect Replicator. 3D Print. Addit. Manuf. 2014, 1, 4-5. [CrossRef]

4. Scan, B. How to Make (Almost) Anything. 2005. Available online: https://www.economist.com/node/ 4031304/print?Story_ID=40313044031304 (accessed on 9 August 2018).

5. Gershenfeld, N. How to Make Almost Anything: The Digital Fabrication Revolution. 2012. Available online: http://cba.mit.edu/docs/papers/12.09.FA.pdf (accessed on 9 August 2018).

6. Markillie, P. A Third Industrial Revolution. 2012. Available online: https:/www.economist.com/specialreport/2012/04/21/a-third-industrial-revolution (accessed on 9 August 2018).

7. Gwamuri, J.; Wittbrodt, B.; Anzalone, N.; Pearce, J. Reversing the Trend of Large Scale and Centralization in Manufacturing: The Case of Distributed Manufacturing of Customizable 3-D-Printable Self-Adjustable Glasses. Chall. Sustain. 2014, 2, 30-40. [CrossRef]

8. Wittbrodt, B.; Laureto, J.; Tymrak, B.; Pearce, J. Distributed Manufacturing with 3-D Printing: A Case Study of Recreational Vehicle Solar Photovoltaic Mounting Systems. J. Frugal Innov. 2015, 1, 1-7. [CrossRef]

9. Woern, A.L.; Pearce, J.M. Distributed Manufacturing of Flexible Products: Technical Feasibility and Economic Viability. Technologies 2017, 5, 71. [CrossRef]

10. Petersen, E.E.; Kidd, R.W.; Pearce, J.M. Impact of DIY Home Manufacturing with 3D Printing on the Toy and Game Market. Technologies 2017, 5, 45. [CrossRef]

11. Petersen, E.E.; Pearce, J. Emergence of Home Manufacturing in the Developed World: Return on Investment for Open-Source 3-D Printers. Technologies 2017, 5, 7. [CrossRef]

12. Wittbrodt, B.T.; Glover, A.G.; Laureto, J.; Anzalone, G.C.; Oppliger, D.; Irwin, J.L.; Pearce, J.M. Life-cycle economic analysis of distributed manufacturing with open-source 3-D printers. Mechatronics 2013, 23, 713-726. [CrossRef]

13. Gallup, N.; Bow, J.K.; Pearce, J.M. Economic Potential for Distributed Manufacturing of Adaptive Aids for Arthritis Patients in the U.S. Geriatrics 2018, 3, 89. [CrossRef]

14. Anderson, P.; Sherman, C.A. A discussion of new business models for 3D printing. Int. J. Technol. Mark. 2007, 2, 280-294. [CrossRef]

15. Laplume, A.; Anzalone, G.; Pearce, J. Open-source, self-replicating 3-D printer factory for small-business manufacturing. Int. J. Adv. Manuf. Technol. 2015, 85, 633-642. [CrossRef]

16. Laplume, A.; Petersen, B.; Pearce, J. Global value chains from a 3D printing perspective. J. Int. Bus. Stud. 2016, 47, 595-609. [CrossRef]

17. Kietzmann, J.; Pitt, L.; Berthon, P. Disruptions, decisions, and destinations: Enter the age of 3-D printing and additive manufacturing. Bus. Horiz. 2015, 58, 209-215. [CrossRef] 
18. Gress, D.R.; Kalafsky, R.V. Geographies of production in 3D: Theoretical and research implications stemming from additive manufacturing. Geoforum 2015, 60, 43-52. [CrossRef]

19. Cappa, F.; Del Sette, F.; Hayes, D.; Rosso, F. How to Deliver Open Sustainable Innovation: An Integrated Approach for a Sustainable Marketable Product. Sustainability 2016, 8, 1341. [CrossRef]

20. Mai, J.; Zhang, L.; Tao, F.; Ren, L. Customized production based on distributed 3D printing services in cloud manufacturing. Int. J. Adv. Manuf. Technol. 2016, 84, 71-83. [CrossRef]

21. Pearce, J. Building Research Equipment with Free, Open-Source Hardware. Science 2012, 337, $1303-1304$. [CrossRef]

22. Pearce, J. Open-Source Lab.: How to Build Your Own Hardware and Reduce Research Costs, 1st ed.; Elsevier: Waltham, MA, USA, 2014.

23. Baden, T.; Chagas, A.; Marzullo, T.; Prieto-Godino, L.; Euler, T. Open Laware: 3-D Printing Your Own Lab Equipment. PLoS Biol. 2015, 13, e1002175.

24. Dhankani, K.C.; Pearce, J.M. Open-source laboratory sample rotator mixer and shaker. HardwareX 2017, 1, 1-12. [CrossRef]

25. Beeker, L.Y.; Pringle, A.M.; Pearce, J.M. Open-source parametric 3-D printed slot die system for thin film semiconductor processing. Addit. Manuf. 2018, 20, 90-100. [CrossRef]

26. Hietanen, I.; Heikkinen, I.T.S.; Savin, H.; Pearce, J.M. Approaches to open-source 3-D printable probe positioners and micromanipulators for probe stations. HardwareX 2018, 4, e00042. [CrossRef]

27. Coakley, M.; Hurt, D.E. 3D Printing in the Laboratory: Maximize Time and Funds with Customized and Open-Source Labware. J. Lab. Autom. 2016, 21, 489-495. [CrossRef] [PubMed]

28. Pearce, J. Quantifying the Value of Open-source Hardware Development. Mod. Econ. 2015, 6, 1-11. [CrossRef]

29. Pearce, J.M. Return on investment for open-source scientific hardware development. Sci. Pub. Policy 2016, 43, 192-195. [CrossRef]

30. Wohlers Report 2016: 3D Printing and Additive Manufacturing State of the Industry Annual Worldwide Progress Report; Wohlers Associates Inc.: Fort Collins, CO, USA, 2016.

31. Baechler, C.; DeVuono, M.; Pearce, J.M. Distributed recycling of waste polymer into RepRap feedstock. Rapid Prototyp. J. 2013, 19, 118-125. [CrossRef]

32. Kreiger, M.; Anzalone, G.C.; Mulder, M.L.; Glover, A.; Pearce, J.M. Distributed recycling of post-consumer plastic waste in rural areas. MRS Online Proc. 2013, 1492, 91-96. [CrossRef]

33. Kreiger, M.A.; Mulder, M.L.; Glover, A.G.; Pearce, J.M. Life cycle analysis of distributed recycling of post-consumer high density polyethylene for 3-D printing filament. J. Clean. Prod. 2014, 70, 90-96. [CrossRef]

34. Zhong, S.; Rakhe, P.; Pearce, J.M. Energy Payback Time of a Solar Photovoltaic Powered Waste Plastic Recyclebot System. Recycling 2017, 2, 10. [CrossRef]

35. Zhong, S.; Pearce, J.M. Tightening the loop on the circular economy: Coupled distributed recycling and manufacturing with recyclebot and RepRap 3-D printing. Resour. Conserv. Recycl. 2018, 128, 48-58. [CrossRef]

36. Recyclebot. Available online: http://www.appropedia.org/Recyclebot (accessed on 9 August 2018).

37. Woern, A.L.; McCaslin, J.R.; Pringle, A.M.; Pearce, J.M. RepRapable Recyclebot: Open-source 3-D printable extruder for converting plastic to 3-D printing filament. HardwareX 2018, 4, e00026. [CrossRef]

38. Cruz Sanchez, F.; Lanza, S.; Boudaoud, H.; Hoppe, S.; Camargo, M. Polymer Recycling and Additive Manufacturing in an Open-source context: Optimization of processes and methods. In Proceedings of the 2015 Annual International Solid Freeform Fabrication Symposium-An Additive Manufacturing Conference, Austin, TX, USA, 10-12 August 2015; pp. 10-12.

39. Cruz Sanchez, F.A.; Boudaoud, H.; Hoppe, S.; Camargo, M. Polymer recycling in an open-source additive manufacturing context: Mechanical issues. Addit. Manuf. 2017, 17, 87-105. [CrossRef]

40. Anderson, I. Mechanical Properties of Specimens 3D Printed with Virgin and Recycled Polylactic Acid. 3D Print. Addit. Manuf. 2017, 4, 110-115. [CrossRef]

41. Pakkanen, J.; Manfredi, D.; Minetola, P.; Iuliano, L. About the Use of Recycled or Biodegradable Filaments for Sustainability of 3D Printing. In Sustainable Design and Manufacturing, Smart Innovation, Systems and Technologies; Springer: Cham, Switzerland, 2017; pp. 776-785.

42. Mohammed, M.I.; Mohan, M.; Das, A.; Johnson, M.D.; Badwal, P.S.; McLean, D.; Gibson, I. A low carbon footprint approach to the reconstitution of plastics into 3D-printer filament for enhanced waste reduction. KnE Eng. 2017, 2, 234-241. [CrossRef] 
43. Mohammed, M.I.; Das, A.; Gomez-Kervin, E.; Wilson, D.; Gibson, I. EcoPrinting: Investigating the use of $100 \%$ recycled Acrylonitrile Butadiene Styrene (ABS) for Additive Manufacturing. In Proceedings of the 28th Annual International Solid Freeform Fabrication Symposium, Austin, TX, USA, 7-9 August 2017.

44. Chong, S.; Pan, G.-T.; Khalid, M.; Yang, T.C.-K.; Hung, S.-T.; Huang, C.-M. Physical Characterization and Pre-assessment of Recycled High-Density Polyethylene as 3D Printing Material. J. Polym. Environ. 2017, 25, 136-145. [CrossRef]

45. Pepi, M.; Zander, N.; Gillan, M. Towards Expeditionary Battlefield Manufacturing Using Recycled, Reclaimed, and Scrap Materials. JOM 2018, 70, 2359-2364. [CrossRef]

46. Zander, N.E.; Gillan, M.; Lambeth, R.H. Recycled polyethylene terephthalate as a new FFF feedstock material. Addit. Manuf. 2018, 21, 174-182. [CrossRef]

47. Hart, K.R.; Frketic, J.B.; Brown, J.R. Recycling meal-ready-to-eat (MRE) pouches into polymer filament for material extrusion additive manufacturing. Addit. Manuf. 2018, 21, 536-543. [CrossRef]

48. Tian, X.; Liu, T.; Wang, Q.; Dilmurat, A.; Li, D.; Ziegmann, G. Recycling and remanufacturing of 3D printed continuous carbon fiber reinforced PLA composites. J. Clean. Prod. 2017, 142, 1609-1618. [CrossRef]

49. Pringle, A.M.; Rudnicki, M.; Pearce, J. Wood Furniture Waste-Based Recycled 3-D Printing Filament. For. Prod. J. 2018, 68, 86-95. [CrossRef]

50. Oblak, P.; Gonzalez-Gutierrez, J.; Zupančič, B.; Aulova, A.; Emri, I. Processability and mechanical properties of extensively recycled high density polyethylene. Polym. Degrad. Stab. 2015, 114, 133-145. [CrossRef]

51. Hyung Lee, J.; Sub Lim, K.; Gyu Hahm, W.; Hun Kim, S. Properties of recycled and virgin poly(ethylene terephthalate) blend fibers. Appl. Polym. Sci. 2012, 128, 2.

52. Beaudoin, A. JMS-1704: Multihead 3D Printer. Ph.D. Thesis, Worcester Polytechnic Institute, Worcester, MA, USA, 2016.

53. Volpato, N.; Kretschek, D.; Foggiatto, J.A.; da Silva Cruz, C.G. Experimental analysis of an extrusion system for additive manufacturing based on polymer pellets. Int. J. Adv. Manuf. Technol. 2015, 81, 1519-1531. [CrossRef]

54. Whyman, S.; Arif, K.M.; Potgieter, J. Design and development of an extrusion system for 3D printing biopolymer pellets. Int. J. Adv. Manuf. Technol. 2018, 96, 3417-3428. [CrossRef]

55. Horne, R. Reprap Development and Further Adventures in DIY 3D Printing: No More Filament? -Quest for a Universal Pellet Extruder for 3D Printing. Reprap Development and Further Adventures in DIY 3D Printing. 2014. Available online: https://richrap.blogspot.com/2014/12/no-more-filament-quest-for-universal.html (accessed on 9 August 2018).

56. Universal Pellet Extruder. Available online: http://upe3d.blogspot.com/ (accessed on 9 August 2018).

57. The PartDaddy-Large Format Delta 3D Printer-Custom. Available online: https://www.seemecnc.com/ products/partdaddy-large-format-delta-3d-printer (accessed on 9 August 2018).

58. Cheetah Pro Large Format 3D Printer by Hans Fouche. Available online: http://www.fouche3dprinting.com (accessed on 9 August 2018).

59. Introducing David. Available online: http://sculptify.com/david (accessed on 9 July 2018).

60. Erecto-Struder 24v, ErectorBot Store. Available online: http://www.erectorbot.com/store/product_info.php? cPath=23\&products_id=65 (accessed on 9 August 2018).

61. Gigabot X: Large-Scale, Recycled Plastic Pellet 3D Printer. Available online: https://www.kickstarter.com/ projects/re3d/gigabot-x-your-direct-pellet-extrusion-3d-printer (accessed on 9 August 2018).

62. Woern, A.L.; Byard, D.J.; Oakley, R.B.; Fiedler, M.J.; Snabes, S.L.; Pearce, J.M. Fused Particle Fabrication 3-D Printing: Recycled Materials' Optimization and Mechanical Properties. Materials 2018, 11, 1413. [CrossRef]

63. Byard, D.J.; Woern, A.L.; Oakley, R.B.; Fiedler, M.J.; Snabes, S.L.; Pearce, J.M. Green fab lab applications of large-area waste polymer-based additive manufacturing. Addit. Manuf. 2019, 27, 515-525. [CrossRef]

64. Fiji Is Just ImageJ. Available online: https://fiji.sc/ (accessed on 9 August 2018).

65. Woern, A.L. Particle Size Analysis Using ImageJ Software: MOST. Available online: http://www.appropedia. org/Particle_Size_Analysis_using_ImageJ_Software:MOST (accessed on 5 November 2019).

66. PC Filament Gizmodorks. Available online: https://gizmodorks.com/polycarbonate-3d-printer-filament/ (accessed on 2 February 2019).

67. Re:3D. Available online: https://github.com/Gigabot-Labs/Pellet-Extruder (accessed on 9 August 2018).

68. Re:3D. Life-Sized Affordable 3D Printing. Available online: https://re3d.org/ (accessed on 9 August 2018).

69. Slic3r-G-Code Generator for 3D Printers. Available online: http://slic3r.org (accessed on 9 August 2018). 
70. Marlin Firmware Download. Available online: http://marlinfw.org/meta/download/ (accessed on 11 February 2019).

71. Open Access Repository for This Study. Available online: https://osf.io/kf4w2/ (accessed on 19 April 2019).

72. Lulzbot Taz 6. Available online: https://www.lulzbot.com/store/printers/lulzbot-taz-6 (accessed on 8 February 2019).

73. Cura Download. Available online: https://ultimaker.com/en/products/ultimaker-cura-software (accessed on 11 February 2019).

74. ASTM D638-14 Type IV Tensile Bars-Horizontal and Vertical by Jpearce-Thingiverse. Available online: https://www.thingiverse.com/thing:2879550 (accessed on 19 April 2019).

75. U.S. Energy Information Administration-Electric Power Monthly. Available online: https://www.eia.gov/ electricity/monthly/epm_table_grapher.php?t=epmt_5_6_a (accessed on 3 August 2018).

76. Mohammed, M.I.; Wilson, D.; Gomez-Kervin, E.; Rosson, L.; Long, J. EcoPrinting: Investigation of Solar Powered Plastic Recycling and Additive Manufacturing for Enhanced Waste Management and Sustainable Manufacturing. In Proceedings of the 2018 IEEE Conference on Technologies for Sustainability (SusTech), Long Beach, CA, USA, 11-13 November 2018; pp. 1-6.

77. Mohammed, M.I.; Wilson, D.; Gomez-Kervin, E.; Vidler, C.; Rosson, L.; Long, J. The Recycling of E-Waste ABS Plastics by Melt Extrusion and 3D Printing Using Solar Powered Devices as a Transformative Tool for Humanitarian Aid. Available online: Sffsymposium.engr.utexas.edu/sites/default/files/2018/007\% 20TheRecyclingofEWasteABSPlasticsbyMeltExtr.pdf (accessed on 19 April 2019).

78. Amazon.com: Wood Floor Steamer. Available online: https://www.amazon.com/s?k=wood+floor+steamer\& ref=nb_sb_noss_ (accessed on 19 April 2019).

79. Bychkov, D. Ice Scraper with Interchangeable Blade. Available online: https://www.thingiverse.com/thing: 3206864 (accessed on 20 January 2019).

80. Stevenson, K. The Other Reason for 3D Printing Pellets. Available online: http://www.fabbaloo.com/blog/ 2018/5/10/the-other-reason-for-3d-printing-pellets (accessed on 9 August 2018).

81. Standardization Administration of the People's Republic of China (SAC) GB16288. Marking of Plastics Products; Chinese Standard Publishing House: Beijing, China, 2008.

82. D20 Committee Practice for Coding Plastic Manufactured Articles for Resin Identification. Available online: https://compass.astm.org/EDIT/html_annot.cgi?D7611+18 (accessed on 9 August 2018).

83. Hunt, E.J.; Zhang, C.; Anzalone, N.; Pearce, J.M. Polymer recycling codes for distributed manufacturing with 3-D printers. Resour. Conserv. Recycl. 2015, 97, 24-30. [CrossRef]

84. Pearce, J.M. Expanding the Consumer Bill of Rights for material ingredients. Mater. Today 2018, 21, 197-198. [CrossRef]

85. Tymrak, B.M.; Kreiger, M.; Pearce, J.M. Mechanical properties of components fabricated with open-source 3-D printers under realistic environmental conditions. Mater. Des. 2014, 58, 242-246. [CrossRef]

86. Tanikella, N.G.; Wittbrodt, B.; Pearce, J.M. Tensile strength of commercial polymer materials for fused filament fabrication 3D printing. Addit. Manuf. 2017, 15, 40-47. [CrossRef]

87. Laureto, J.J.; Pearce, J.M. Anisotropic mechanical property variance between ASTM D638-14 type i and type iv fused filament fabricated specimens. Polym. Test. 2018, 68, 294-301. [CrossRef]

88. Giberti, H.; Sbaglia, L. A Robotic Design for a MIM Based Technology. In Advances in Service and Industrial Robotics; Mechanisms and Machine Science; Springer: Cham, Switzerland, 2017; pp. 565-572.

89. Giberti, H.; Sbaglia, L.; Silvestri, M. Mechatronic Design for an Extrusion-Based Additive Manufacturing Machine. Machines 2017, 5, 29. [CrossRef]

90. Liu, X.; Chi, B.; Jiao, Z.; Tan, J.; Liu, F.; Yang, W. A large-scale double-stage-screw 3D printer for fused deposition of plastic pellets. J. Appl. Polym. Sci. 2017, 134, 45147. [CrossRef]

91. Braanker, G.B.; Duwel, J.E.P.; Flohil, J.J.; Tokaya, G.E. Developing a Plastics Recycling Add-on for the RepRap 3D-Printer. 2010. Available online: https://reprapdelft.files.wordpress.com/2010/04/reprap-granule-extrudertudelft1.pdf (accessed on 9 August 2018).

92. Wang, Z.; Liu, R.; Sparks, T.; Liou, F. Large-Scale Deposition System by an Industrial Robot (I): Design of Fused Pellet Modeling System and Extrusion Process Analysis. 3D Print. Addit. Manuf. 2016, 3, 39-47. [CrossRef]

93. Kumar, N.; Jain, P.K.; Tandon, P.; Pandey, P.M. Extrusion-based additive manufacturing process for producing flexible parts. J. Braz. Soc. Mech. Sci. Eng. 2018, 40, 143. [CrossRef] 
94. Kumar, N.; Jain, P.K.; Tandon, P.; Pandey, P.M. Additive manufacturing of flexible electrically conductive polymer composites via CNC-assisted fused layer modeling process. J. Braz. Soc. Mech. Sci. Eng. 2018, 40, 175. [CrossRef]

(). 1

(C) 2019 by the authors. Licensee MDPI, Basel, Switzerland. This article is an open access article distributed under the terms and conditions of the Creative Commons Attribution (CC BY) license (http://creativecommons.org/licenses/by/4.0/). 